\title{
Sequential Photodamage Driven by Chaotic Systems in NiO Thin Films and Fluorescent Human Cells
}

\author{
Hilario Martines-Arano ${ }^{1}$, Mónica Araceli Vidales-Hurtado ${ }^{2}$ (D) , Samara Palacios-Barreto ${ }^{3}$, \\ Martín Trejo-Valdez ${ }^{4}$, Blanca Estela García-Pérez ${ }^{3}(1)$ and Carlos Torres-Torres $1, *(1)$ \\ 1 Sección de Estudios de Posgrado e Investigación, Escuela Superior de Ingeniería Mecánica y Eléctrica \\ Unidad Zacatenco, Instituto Politécnico Nacional, 07738 Ciudad de México, Mexico; \\ hmartinesa1500@alumno.ipn.mx \\ 2 Centro de Investigación en Ciencia Aplicada y Tecnología Avanzada Unidad Querétaro, Instituto Politécnico \\ Nacional, Santiago de Querétaro, 76090 Querétaro, Mexico; mvidales@ipn.mx \\ 3 Departamento de Microbiología, Escuela Nacional de Ciencias Biológicas, Instituto Politécnico Nacional, \\ 11340 Ciudad de México, Mexico; spalaciosb1300@alumno.ipn.mx (S.P.-B.); blgarciap@ipn.mx (B.E.G.-P.) \\ 4 Escuela Superior de Ingeniería Química e Industrias Extractivas, Instituto Politécnico Nacional, \\ 07738 Ciudad de México, Mexico; mtrejov@ipn.mx \\ * Correspondence: ctorrest@ipn.mx; Tel.: +52-55-57-29-60-00 (ext. 54686)
}

Received: 30 September 2020; Accepted: 26 October 2020; Published: 29 October 2020

\begin{abstract}
A laser ablation process assisted by the feedback of a sensor with chaotic electronic modulation is reported. A synchronous bistable logic circuit was analyzed for switching optical signals in a laser-processing technique. The output of a T-type flip-flop configuration was employed in the photodamage of $\mathrm{NiO}$ films. Multiphotonic effects involved in the ablation threshold were evaluated by a vectorial two-wave mixing method. A photoinduced thermal phenomenon was identified as the main physical mechanism responsible for the nonlinearity of index under nanosecond irradiation at $532 \mathrm{~nm}$ wavelength. Comparative experiments for destroying highly transparent human cells were carried out. Potential applications for developing hierarchical functions yielding laser-induced controlled explosions with immediate applications for biomedical photothermal processes can be contemplated.
\end{abstract}

Keywords: laser ablation; optical Kerr effect; two-wave mixing; photodamage; semiconductor processing; $\mathrm{NiO}$; thin films; human cells

\section{Introduction}

Recent developments in the field of laser ablation of advanced materials have led to a renewed interest in fascinating applications for device fabrication in nanoelectronics [1], integrated photonics [2], and low-dimensional sensors [3]. Results provided by continuous wave (CW) laser systems compared to pulsed lasers can be enumerated in respect to power or selectivity in their photodamage [4].

CW and ultra-short laser sources present remarkable differences in optical damage [5]. Particularly, potential actions of optical nonlinearities [6], shock waves [7], plasma phenomena [8], or temperature conditions [9] can be responsible for the dynamics of photoenergy transfer exhibited by high-irradiance phenomena. On the other hand, the pulse repetition rate in photodamage can play a crucial role associated with the physical mechanisms of thermal transport in optical materials [10].

On the other hand, the precision in photodamage of bidimensional materials is an attractive topic for tuning their physical and chemical characteristics strongly dependent on size and shape of nanostructures. Thin solid films with characteristics modulated by optical and electrical effects have been pointed out for sensing and instrumentation functions [11]. In this direction, $\mathrm{NiO}$ films have 
reversible changes in optical absorption induced by electric fields [12]. Electrochromic NiO devices can store and display information with a memory effect [13]. Besides, electrical properties exhibited by $\mathrm{NiO}$ materials have received considerable attention due to their multifunctional conductivity [14]. The band gap energy of $\mathrm{NiO}$ is in the range of 3.6-4 eV, together with high transparency under particular electrical conditions [15]. Some important applications of $\mathrm{NiO}$ are represented by catalyst in electrochemical cells [16] or electrode materials for lithium ion batteries [17]. Typically, $\mathrm{NiO}$ films in appropriate atmospheres can change their colors as a function of an electric field [18]. Electrochemical energy storage applications of $\mathrm{NiO}$ [19] and solar cells [20] are associated with chemical stability and nontoxicity [21].

In order to improve photothermal processing in materials science, diverse optical sensors assisted by self-feedback have been studied [22]. Analog and digital circuits have been extensively explored, taking into account sophisticated algorithms for sensing [23]. With these considerations, it has been indicated the advantage of sensitivity to initial conditions' functions detected by sensors governed by a chaotic modulation [24].

Despite the fact that a chaotic system is considered as an attractor in state space [25], it is usually hard to determinate its behavior [26]. There are representative examples of 3-D chaotic systems, such as Lorenz [27], Sprott [28], Chen [29], or Rössler [30]. However, recent trends in the Rössler system have indicated a potential progress for engineering medical applications [31]. Moreover, some important implementations for Rössler systems are ultrafast signal processing [32], remote sensing image [33], and transformation of biological DNA sequence [34]. Relevant applications in this direction such as optoelectronic sensing [35], all-optical codification [36], probabilistic [37], telecom [38], and artificial intelligence [39] are based on chaotic models.

Our research question in this work arose by the continuous demand of high accuracy in photodamage techniques. Collateral optical damage derived by heat propagation can be avoided by using a feedback. In this respect, we present in this work the advantages of chaos theory employed in laser ablation processes assisted by sensors. In view of all these motivations, this work was devoted to further investigate chaotically modulated optoelectronic signals for sensing and controlling photodamage induced in $\mathrm{NiO}$ thin films exposed to nanosecond laser ablation. A multivibrator circuit was employed for switching the photothermal laser damage of the sample irradiated at a $532 \mathrm{~nm}$ wavelength. Alternative experiments of laser ablation were discussed by conducting comparative processes of damage induced by optical irradiation in highly transparent human cells. Potential applications of the proposed technique in material science processing and biomedical laser technology can be envisioned.

\section{Materials and Methods}

\subsection{Synthesis of the NiO Samples}

The $\mathrm{NiO}$ films were obtained by the ultrasonic spray pyrolysis technique, from an aqueous solution of nickel acetate tetrahydrate $0.05 \mathrm{M}$ mixed with polyethylene glycol, in a 5:1 ratio. ITO-coated glass with sheet resistance of 15-25 ohm (Delta Technologies, Inc., Loveland, CO, USA) was used as substrates. The deposit was made by using an ultrasonic nozzle (Sonaer) operated at $130 \mathrm{kHz}$. Compressed air (10 psi) was employed to conduct the flow over the substrate, which was maintained at a temperature of $250^{\circ} \mathrm{C}$ over a molten tin bath. The nozzle-to-substrate distance was fixed at $8 \mathrm{~cm}$ with a flow of $1 \mathrm{~mL} / \mathrm{min}$. During spraying, the nozzle was in constant motion in the $\mathrm{XY}$ plane, following an "S"-shaped geometry and covering the entire surface of the substrate in a round-trip cycle; 50 cycles were given with intervals of $2 \mathrm{~min}$. The $\mathrm{NiO}$ thin films with $110 \mathrm{~nm}$ average thickness were selected for carrying out the optical and electrical experiments. Transmission electron microscopy (TEM) studies were undertaken by a JEM-ARM200CF\&Gatan Ultrascan 1000XP system. Scanning electron microscopy (SEM) observations were conducted by using a FEG Quanta 3D FEI microscope system in scanning transmission electron microscopy (STEM) mode. Electrochemical impedance spectroscopy 
measurements were performed in the NiO thin films by an AUTOLAB 302N PGSTAT potentiostat. Three-electrode cells composed by comparative $\mathrm{NiO}$ thin film samples of $1 \mathrm{~cm}^{2}$ surface area, an $\mathrm{Ag} / \mathrm{AgCl}$ electrode [40], and a platinum electrode were employed. A 0.5 M KOH solution was used as a support electrolyte, which, before experimental stage, was previously degassed in an ultrasonic bath for $15 \mathrm{~min}$ and bubbled with nitrogen gas for another $10 \mathrm{~min}$. Direct current (DC) voltage was utilized to study the semiconductor-electrolyte interface properties. Spectrophotometric studies were carried out by a Perkin Elmer UV/VIS XLS system. The film samples were analyzed through spectroscopic ellipsometry. We used an uvisel ellipsometer model LT M200AGMS HORIBA brand Jobin Yvon. The sample was placed in the equipment sample holder. We used parameters such as xenon lamp at high pressure of $75 \mathrm{~W}, 70^{\circ}$ as angle of incidence, laser spot of $1200 \mu \mathrm{m}$, and a spectral range of $1.5-5.5 \mathrm{eV}$. Furthermore, spectroscopic ellipsometry used an increase of $0.0500 \mathrm{eV}$ and 81 points; the device was configured to acquire information through reflection method.

\subsection{Electronic Sensing of the Sample by Steady-State Rössler Attractors}

The Rössler model can be mathematically described by three differential equations [41]:

$$
\begin{gathered}
\frac{d x}{d t}=-(y+z) \\
\frac{d y}{d t}=(x+\mathrm{a} y) \\
\frac{d z}{d t}=\mathrm{b}+z(x+\mathrm{c})
\end{gathered}
$$

where $a, b, c \in \mathbb{R}$ and they correspond to positive values and parameters dimensionless [42]. The magnitudes for $x, y$, and $z$ denote the state variables. We employed the Rössler differential equations that illustrate a continuous-time dynamic with chaotic behavior. Figure 1a represents the Rössler chaotic system as a block diagram, based on Equations (1)-(3). The initial conditions can correspond to $\mathrm{a}=\mathrm{b}=0.2$ and $\mathrm{c}=5.7$, while $x, y$, and $z$ are the three variables that evolve with the time [43]. On the other hand, $x, y$, and $z$ determine the phase space. Equations (1) and (2) have linear terms that create oscillations in the variables $x$ and $y$. Equation (3) has only one nonlinear term with the chaotic behavior as a function of $x$ and $z$. The Matlab software together with an electronic card NI USB 6008 in a laptop can be used for generating the electronic modulation with an emerging chaotic behavior. The input for the block $\mathrm{z}$ is provided by the sensor testing the sample. This signal is calibrated to satisfy the nonlinear dynamics associated with the solutions obtained for Equations (1)-(3). Any change in the electrical conditions of the explored sample originates instability in the Rössler attractor that corresponds to the electronic sensor.

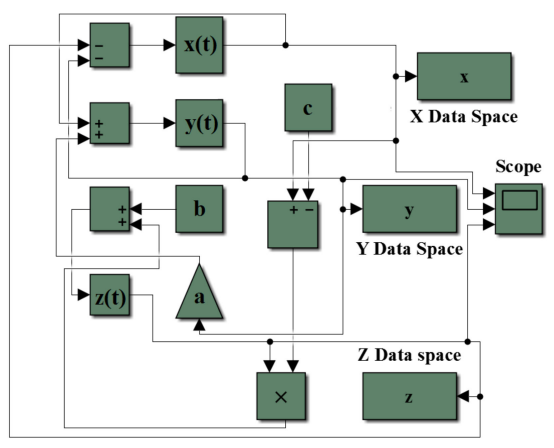

(a)

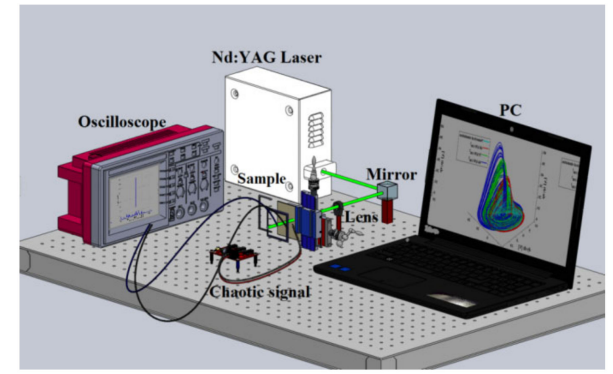

(b)

Figure 1. (a) Experimental procedure block diagram for implementing a Rössler attractor system. (b) Schematic illustration of the laser ablation experiment controlled by a T-type flip-flop with a steady-state Rössler attractor as an input signal. 


\subsection{Laser Ablation Controlled by a T-Type Flip-Flop with a Steady-State Rössler Attractor as an Input Signal}

The second harmonic of a Nd:YAG laser system (Continuum Model SL II) was employed to irradiate the $\mathrm{NiO}$ studied samples. In Figure $1 \mathrm{~b}$ is illustrated the experimental setup. A focused beam of $1 \mathrm{~mm}$ diameter and single shots at $532 \mathrm{~nm}$ wavelength featuring 4 nanosecond pulse duration were employed in the ablation experiments. The sample under optical irradiation was located in a micrometric mechanical mount with carbon electrodes deposited to detect changes in their electrical conductivity before and after the ablation threshold was achieved during the optical incidence.

Moreover, in order to guarantee a total ablation process of the target, the electrical signals connected to the sample were monitored by sequential correlation, as described in Section 2.2. Initial steady state of the Rössler attractor in these measurements was defined by a 0 logic magnitude. The change from steady state to instability, or the other way round, corresponded to a logic value equal to 1 . With these considerations, an electronic circuit with two stable states was proposed for sensing the target. According to the input of the circuit interrogator, a digital output was generated by the assistance of a clock trigger. We selected a T-type flip-flop in our system, regarding that it allows automatic sequential decisions for the ablation process. The T-type flip-flop gives an output by considering the previous state of the sensor. However, the system can dispense with the T-type flip-flop when the ablation is assisted by asynchronous feedback.

The block diagram of the electronically controlled laser ablation system is presented in Figure 2.

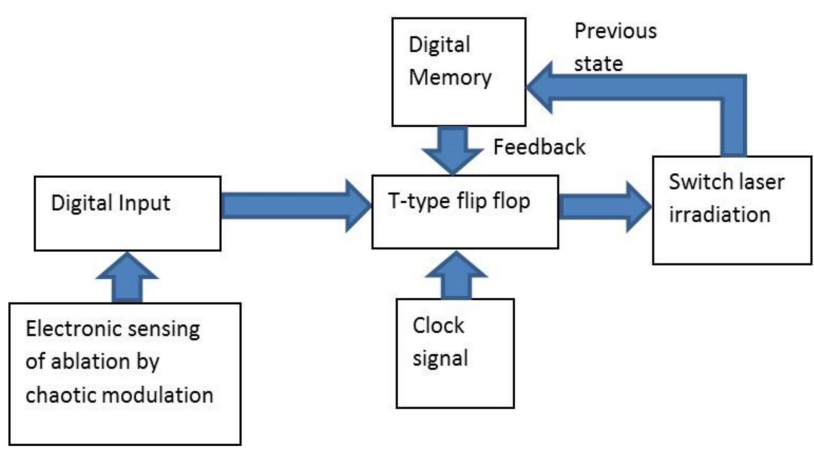

(a)

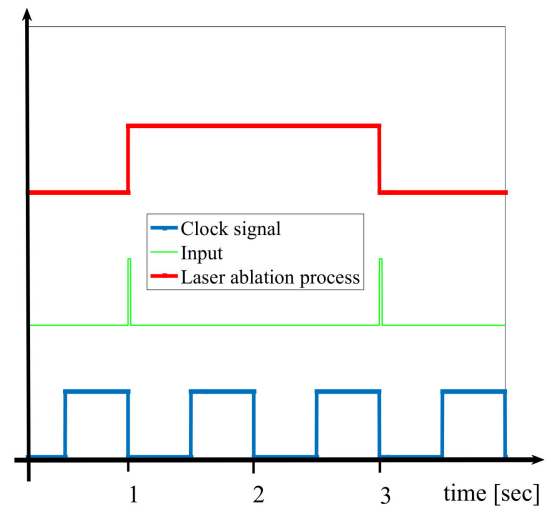

(b)

Figure 2. (a) Procedure diagram for fulfilling a complete laser ablation process controlled by a T-type flip-flop with a steady-state Rössler attractor as an input signal. (b) Chronogram showing the logic digital response during the evolution of laser ablation of the region irradiated. The input is provided by the optoelectronic sensor with chaotic modulation. The clock signal is strobed by a descendent edge trigger in order to avoid metastability.

The transitions between the present to the next states are ruled by a clock. The clock was emulated by a computer and defined, taking into account the time for exploration of each region of the sample at $1 \mathrm{~Hz}$. The positive logic input of the flip-flop is the digital value assigned to the change between stability and instability in the chaotically modulated electronic signals. The output controls the switching of the laser system irradiating the sample (turned on or turned off). Inputs changing from 0 to 0 or from 1 to 1 do not produce switching of the laser. If the input value goes from 0 to 1 , the next state is 1 in the output and the laser signal is turned on. If the input evolves from 1 to 0 , the next state turns off the laser signal.

\subsection{Nonlinear Optical Absorption Studies by a Vectorial Two-Wave Mixing}

A vectorial two-wave mixing technique was used to identify any potential optical nonlinearity that could be a significant contribution in the laser ablation process [43]. Our nanosecond Nd:YAG laser system at $532 \mathrm{~nm}$ wavelength was employed as an optical source with $10 \mathrm{~mJ}$ of maximum pulse energy 
and a focused beam waist of $1 \mathrm{~mm}$ diameter in the sample. The pump and probe beams presented an irradiance relation of 1:1. The polarization of the probe beam was fixed while the polarization of the pump beam was varied by a half-wave plate. A polarizer with its transmission axis orthogonal to the incident polarization of the probe beam in absence of the pump beam was located behind the sample. In order to explore the vectorial nature of the two-beam interaction, the transmitted probe beam through the polarizer as a function of the relative angle between the linear polarizations of the incident beams was analyzed. The geometric incident angle of each beam in the sample was approximately $15^{\circ}$. An error bar of $\pm 10 \%$ in the measurements of irradiance was estimated. For the calibration of the third-order nonlinear optical measurements, a $\mathrm{CS}_{2}$ sample contained in a quartz cuvette with $1 \mathrm{~mm}$ thickness was considered. The magnitude of the third-order nonlinear optical susceptibility in the $\mathrm{CS}_{2}$ is $\left|\chi^{(3)}\right|=1.9 \times 10^{-12}$ esu [44].

The wave equation was used to represent the propagation of the beams through the samples [44]:

$$
\nabla^{2} E_{ \pm}=-\frac{n_{ \pm}^{2} \omega^{2}}{c^{2}} E_{ \pm}
$$

where, according to the literature, $\omega$ is the optical frequency of light and $c$ is the free space of light, whereas the right and left circular components of the electric field are described by $E_{+}$and $E_{-}$, respectively. The refractive index can be expressed as [44]:

$$
n_{ \pm}^{2}=n_{0}^{2}+4 \pi\left(A\left|E_{ \pm}\right|^{2}+(A+B)\left|E_{\mp}\right|^{2}\right)
$$

where $A=\chi_{1122}^{(3)}$ and $B=\chi_{1221}^{(3)}$ represent the components of the third-order susceptibility tensor, whereas $n_{0}$ refers to the weak-field refractive index.

The relationship between the nonlinear refractive index, $n_{2}$, and the nonlinear optical absorption coefficient, $\beta$, with $\chi^{(3)}$ for a particular wavelength, $\lambda$, can be described by [45]:

$$
\chi^{(3)}=\frac{n_{0} c}{7.91 \times 10^{2}} n_{2}+i \frac{n_{0}^{2} c \lambda}{\pi^{2}} \beta
$$

\subsection{Photothermal Distribution in the Film due to Laser Heat Source}

With the intention of estimating the temperature distribution on the film surface, numerical simulations of the temperature calculated by Fourier's law for multidimensional extension were carried out. We considered the general heat conduction equation [46].

$$
\rho C \frac{\partial T}{\partial t}-\nabla(k \nabla T)=Q
$$

where $\rho$ is the density, $C$ is the heat capacity, $k$ represents the thermal conductivity, $Q$ is the total equivalent heat caused by laser irradiation, and $T$ is the temperature, while $t$ is the time. In a photothermal process, it can be considered the heat conduction equation as [46].

$$
Q(x, y)=(1-R) I_{0} \alpha e^{-\alpha}
$$

In this case, $I_{0}$ represents the optical incident irradiance, $R$ is the reflectance, and $\alpha$ denotes the absorbance coefficient.

\section{Results}

The film thickness of the samples was analyzed by SEM observations and spectroscopic ellipsometry. According to the ellipsometry analysis, the sample thickness size was estimated to be $\sim 110 \mathrm{~nm}$. Figure 3a shows a representative image where it is clear that a cross section the NiO film 
was deposited onto the ITO substrate. In Figure $3 b$, the thickness of the film can be better visualized by the green lines in the edges.

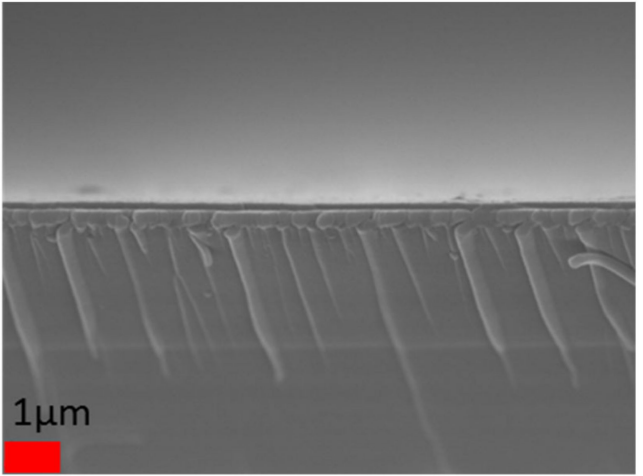

(a)

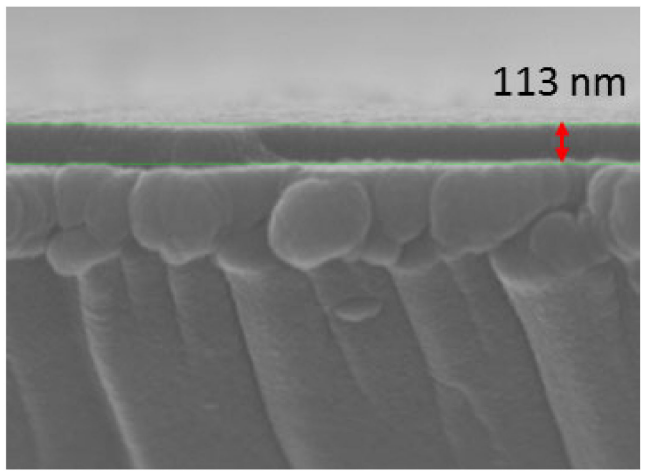

(b)

Figure 3. (a) Representative SEM image of the studied NiO thin film. (b) Amplification of (a) with green lines describing the thickness of the film.

In order to characterize the electrical response of the sample to design the electrical parameters for implementing the electronic sensor, the electrical impedance of the $\mathrm{NiO}$ sample as a function of electrical frequency was recorded. In Figure $4 \mathrm{a}$ is plotted the electrochemical impedance measurements in the $\mathrm{NiO}$ films. A monotonic decrease in the electrical impedance was present in the spectrum; the higher electric impedance emerged for lower electrical frequencies. This electrical behavior, shown in Figure 4a, is usually displayed by circuits with both resistance and capacitive contributions. The evolution of the electrical current as a function of the electrical potential in the NiO sample in $0.5 \mathrm{M} \mathrm{KOH}$ solution can be observed with the DC voltammogram obtained in the $\mathrm{NiO}$ thin film and presented in Figure $4 \mathrm{~b}$. It is a typical example of current null evolution from +0.7 to $-0.45 \mathrm{~V}$ vs. $\mathrm{Ag} / \mathrm{AgCl}$. This low residual current must result from very low defects on the surface of the film and a high crystallinity degree of phase that composed the $\mathrm{NiO}$ film. Once the potential turned toward a cathodic value, a reduction in the data was observed at $-0.5 \mathrm{~V}$ and their current decreased until the onset. This cathodic onset is generally attributed to the hydrogen evolution, whereas the anodic maximal current that is due to oxidation of film material was observed in our case for potential values higher than $0.7 \mathrm{~V}$.

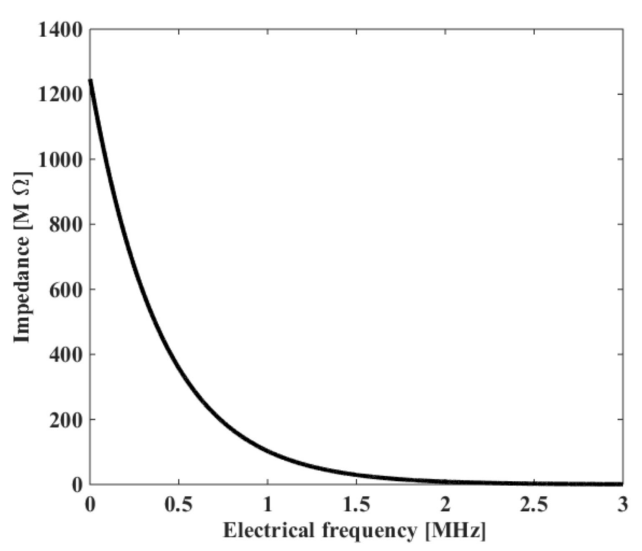

(a)

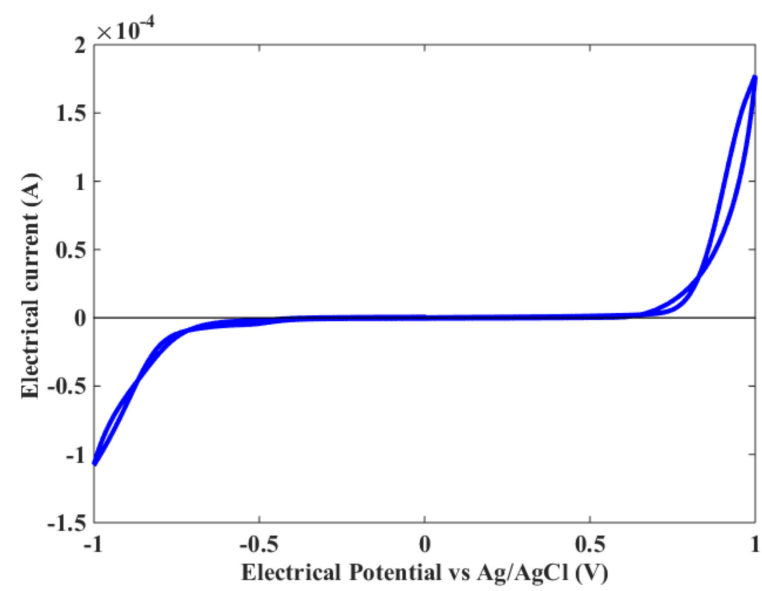

(b)

Figure 4. (a) Electrochemical impedance spectrum of the NiO film. (b) Direct current (DC) cyclic voltammetry of a $\mathrm{NiO}$ film in $0.5 \mathrm{M} \mathrm{KOH}$ solution. The starting potential was $0 \mathrm{~V}$, upper potential was $+1 \mathrm{~V}$, lower potential was $-1 \mathrm{~V}$, and the applied scan rate was $10 \mathrm{mV} / \mathrm{s}$. 
From Figure 4 it can be deduced that the electrical behavior exhibited by our $\mathrm{NiO}$ films is a feature that can be contemplated for enhancing energy storage electrode materials. The capacitive nature of $\mathrm{NiO}$ films is due to reversible charge transfer reactions (oxidation-reduction) that occur on their surface, under an applied voltage. In the presence of $\mathrm{KOH}$, as an electrolyte, the reaction that takes place is: $\mathrm{NiO} \rightarrow \mathrm{NiOOH}+\mathrm{e}-$. The data plotted in Figure $4 \mathrm{~b}$ display hysteresis as an inherent electrical characteristic of this $\mathrm{NiO}$ film material. The development of faradaic-controlled, supercapacitive, and pseudocapacitive energy storage devices implies the ability to overcome the great challenge of decreasing their degradation that can be induced by corrosion or optical ablation and increasing their cycling stability.

In order to evaluate the optical absorption of the $\mathrm{NiO}$ thin film, UV-vis spectroscopy measurements were undertaken. The UV-vis absorbance of the samples is depicted in Figure 5a. The high transparency of the samples can be deduced from the small absorbance in the optical region of the electromagnetic spectrum with strong absorbance in the UV region close to $300 \mathrm{~nm}$. The refractive index of the film was measured by ellipsometry, and $n_{0}=1.65$ was obtained at $532 \mathrm{~nm}$ in the wavelength that the ablation process was considered to be in action. Moreover, the participation of multiphotonic effects during the nanosecond pulsed irradiation was evaluated by a vectorial two-wave mixing experiment. Figure $5 \mathrm{~b}$ shows the transmitted probe irradiance in the two-wave mixing as a function of the angle between the planes of polarization of the probe and pump beams. The magnitude of the third-order nonlinear optical susceptibility in the sample was calculated by a direct comparison with a calibrated $\mathrm{CS}_{2}$ sample. By the best fitting of Equation (4), it can be obtained a $\left|\chi^{(3)}\right|=2.05 \times 10^{-10}$ esu. Since only change in polarization and no change in the total transmittance of the probe beam were observed by the influence of the high-irradiance interaction in the sample, it can be stated that the nonlinear optical absorption can be neglected as a physical mechanism of third-order optical nonlinearity. Besides, the identification of $B=0$ in the numerical fitting corresponded to an isotropic mechanism responsible for the optical nonlinearity of index [44]. Regarding that a self-defocusing effect was observed in the transmitted beams after the two-wave mixing experiment, a negative sign in $n_{2}$ was assumed to correspond with the fitting of the nonlinear refraction. Then, we calculated the optical Kerr effect by Equation (6) and we obtained $n_{2}=-1.99 \times 10^{-12} \mathrm{~cm}^{2} / \mathrm{W}$, which is in good agreement with comparative z-scan measurements in $\mathrm{NiO}$ films [47].

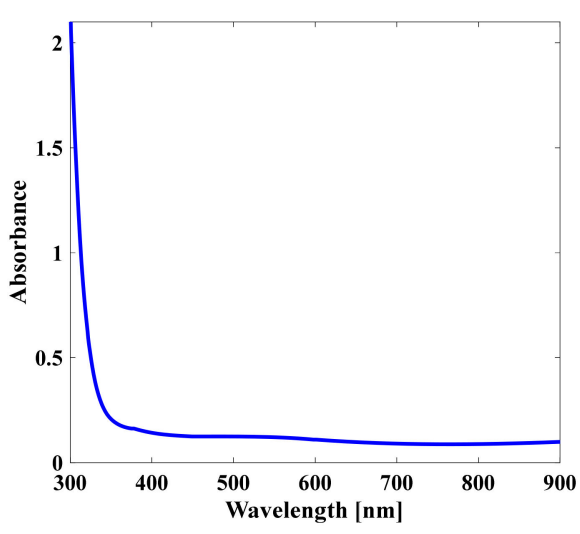

(a)

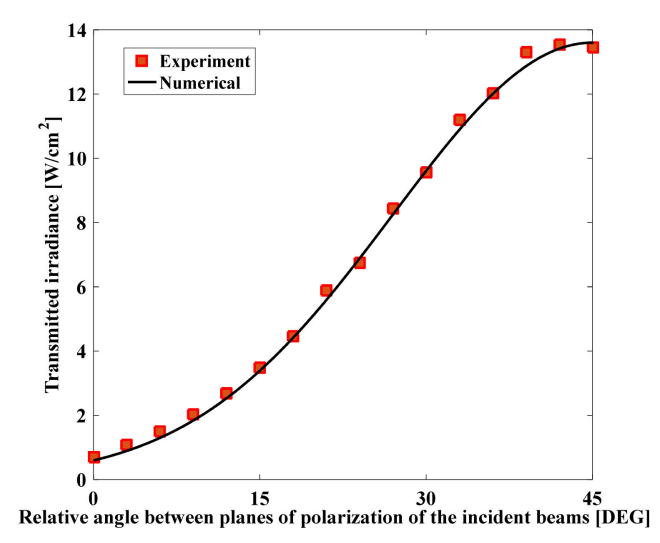

(b)

Figure 5. (a) UV-vis absorbance of the NiO thin films. (b) Nanosecond transmitted probe irradiance as a function of the relative angle of polarization between the incident beams at a $532 \mathrm{~nm}$ in the $\mathrm{NiO}$ thin film.

The temperature analysis for the surface of the thin film was estimated by Equations (7) and (8). Representative TEM images in bright field mode acquired in the $\mathrm{NiO}$ films were considered for the thermal transfer estimations before the ablation process. Figure 6a illustrates a typical TEM micrograph of the $\mathrm{NiO}$ films and Figure $6 \mathrm{~b}$ depicts the temperature distribution associated with the 
selected regions of the TEM observations after receiving a single shot by a nanosecond pulse of $532 \mathrm{~nm}$ during the irradiation stage. The numerical results suggest that the temperature propagation rate was not uniform on the thin film surface. The photothermal energy transfer in the studied thin film irradiated by the laser source was calculated from the balance of heat transport by means of film and substrate. Evidently, radial heat dissipation within the film plane gave a major contribution because it varied in proportion with film thickness. As a consequence, the temperature depended on the film thickness and became higher for thin films. We considered an extension of approximately $25 \mathrm{~nm}$ to perform the simulation.

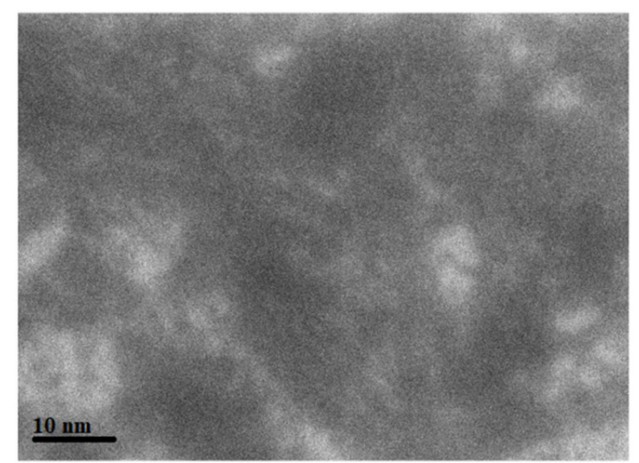

(a)

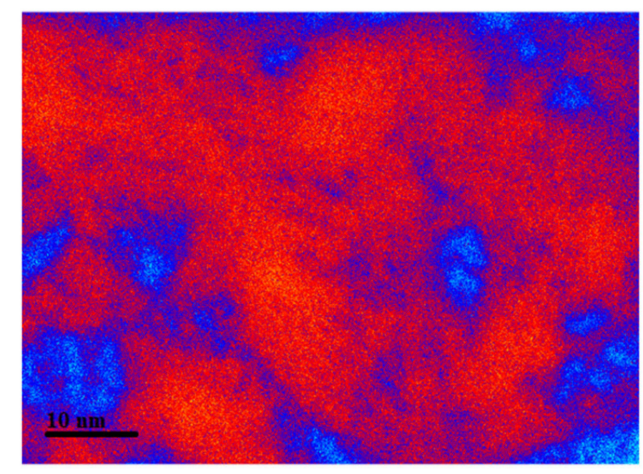

(b)

Figure 6. Micrograph images of a thin, solid film sample studied, showing the surface in bright color. (a) TEM micrograph image before the ablation takes place. (b) Heat distribution (numerical simulation) over a small area interacting with the nanosecond single beam at $532 \mathrm{~nm}$.

It is necessary to clarify that numerical simulations represented by Figure $6 \mathrm{~b}$ correspond to the heat transfer on the surface of a sample, taking into account the conditions of our laser irradiation experiment.

The ablation threshold of the sample was measured by direct incidence of single shots provided by our nanosecond $532 \mathrm{~nm}$ pulses during the simultaneous propagation of the electronic modulated signals by the experimental setup described in Figure 1b. Due to the optical irradiation, steady state of the Rössler attractor exploring the sample evolved to instability under the influence of the ablation process during the experiment. Variation in transmittance in the $\mathrm{NiO}$ thin films occurred at the beginning of the ablation in the area illuminated, and the proximity with the ablation threshold in the sample did affect directly its electrical stability. The sensing of the ablation threshold was guaranteed as a change in the attractor of the circuit. A small change in the electrical response of the $\mathrm{NiO}$ thin film under photodamage caused a change in the attractor. During steady state, the signal recording the electrical response of the sample generated in the system a convergence toward a periodic orbit, around fixed points, or diverging in an escape toward infinity when ablation occurred. Experimental results are shown in Figure 7 . The values of $\mathrm{I}_{0}$ and $2 \mathrm{I}_{0}$ correspond to optical irradiances that represent steady state of the $\mathrm{NiO}$ sample under nanosecond irradiation at a $532 \mathrm{~nm}$ wavelength. Actually, $\mathrm{I}_{0}$ can be calibrated to be just the minimal resolution of the optical detection or the noise and $2 \mathrm{I}_{0}$ is defined in this work as the maximum irradiance in propagation through the sample before the ablation takes place. 


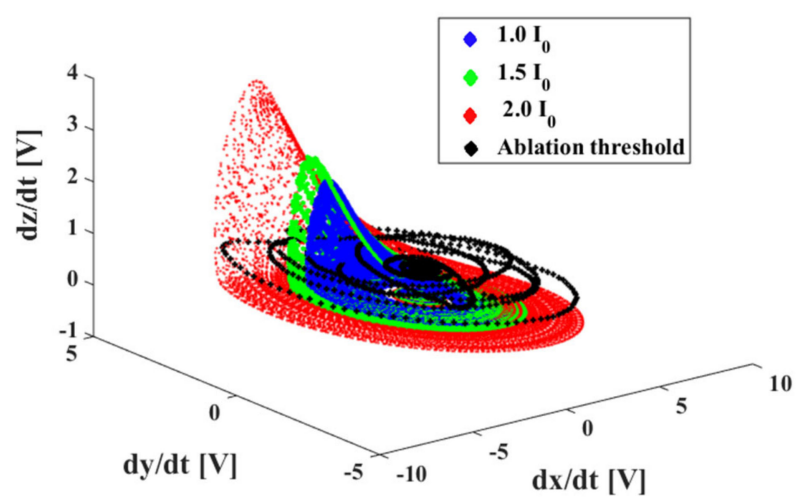

Figure 7. Experimental data obtained by chaotic modulation in conductivity measurements. The data in black show a plot with unstable behavior, due to the ablation threshold reached in the NiO sample during optical irradiation by nanosecond pulses at $532 \mathrm{~nm}$ wavelength.

It is worth noting that laser intensities below the ablation threshold did not remove bulk mass suitable for micro chemical analysis; however individual atoms or ions may be removed or desorbed from the sample surface. Statistical results related to the ablation threshold measured in different points of the sample resulted in a fluence of $1.09 \mathrm{~J} / \mathrm{cm}^{2} \pm 4 \%$. Considering our nanosecond pulses, $2 \mathrm{I}_{0}$ corresponded to a magnitude below $272 \mathrm{MW} / \mathrm{cm}^{2}$.

The technique was initially validated in a $\mathrm{NiO}$ nanofilm with constant conductivity and electrical impedance parameters. Then, we proceeded to study the ablation process, assisted by our sensor in human cells with variable electrical conditions.

To further investigate the potential applications of the sequential photodamage technique proposed in this work, human osteoblasts cells and human B lymphocytes (Raji cells) were selected to be irradiated. Biomarkers incorporated into the biological samples were only present for microscopy observations. In Figure 8a are shown confocal images of the human osteoblasts cells studied. Figure 8b,c shows optical microscopy images of the Raji cells before and after the ablation threshold was achieved.

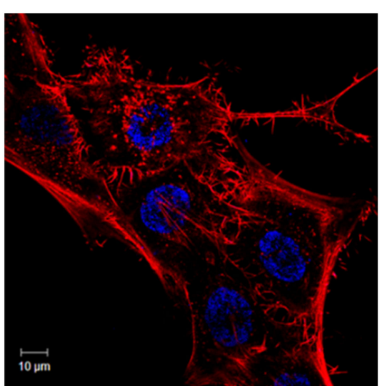

(a)

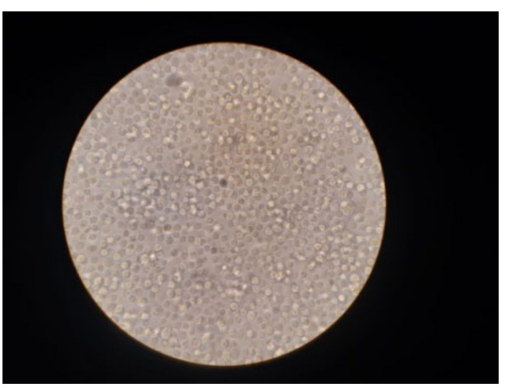

(b)

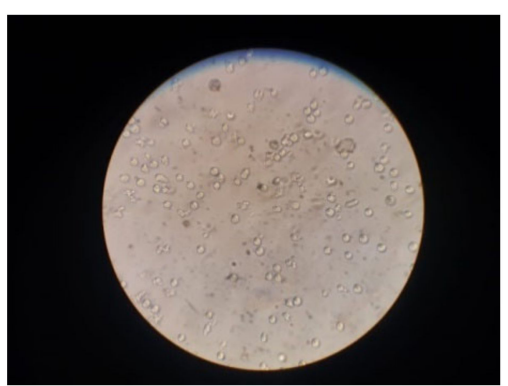

(c)

Figure 8. (a) Confocal image of the human osteoblasts cells studied. The red fluorescence was provided in actin cytoskeleton by rhodamine-phalloidin, while cells nuclei stained by DAPI were detected in blue emission. (b) Optical micrograph of the Raji cells studied before laser ablation. (c) Raji cells after laser ablation threshold.

The nanosecond ablation was statistically measured at $532 \mathrm{~nm}$ by single shots in the different cells focused in $1 \mathrm{~mm}^{2}$. A fluence of $1.52 \mathrm{~J} / \mathrm{cm}^{2} \pm 4 \%$, which corresponded to approximately $382 \mathrm{MW} / \mathrm{cm}^{2}$, was determined as the average of the ablation threshold with equivalent absorbance 0.238 for the comparative studied samples. The results related to the identification of the steady state of the samples irradiated and the conditions of ablation are shown in Figure 9. 


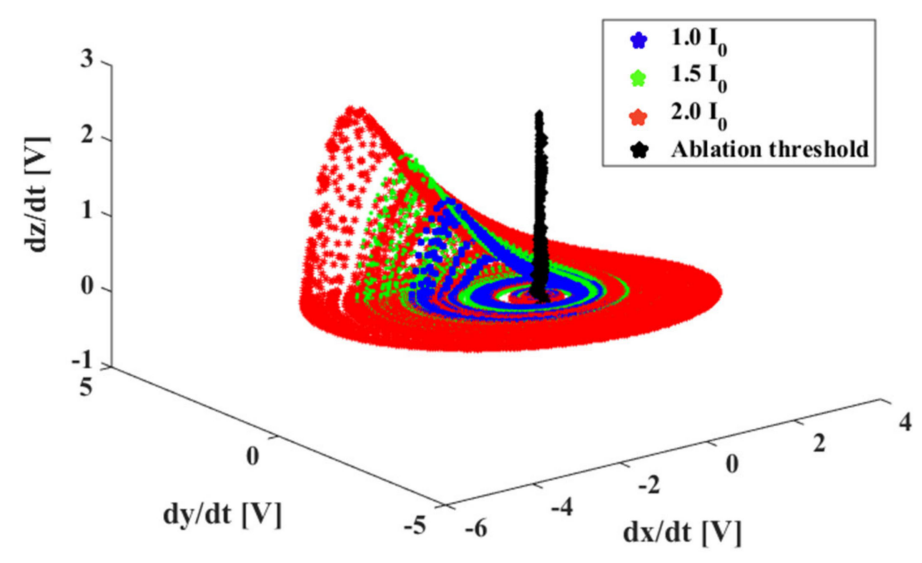

Figure 9. Typical experimental data obtained by chaotic modulation in conductivity measurements. The data in black show a plot with instable behavior, due to the ablation threshold reached in the osteoblast cells during optical irradiation by nanosecond pulses at $532 \mathrm{~nm}$ wavelength. Similar results were obtained for the Raji cells, marking the importance of the absorbance of the samples for reproducibility of the results.

The cells were integrated in a homogeneous monolayer for the nanosecond ablation experiment. However, for the ablation threshold condition shown in Figure 8c, the incomplete evaporation of the total distribution of cells in the sample should be derived by inherent properties related to the Gaussian beam profile, scattering, and nonlinear energy transfer. In order to guarantee the total evaporation of the studied samples, the procedure described in Section 2.3 was conducted and a train of pulses at $10 \mathrm{~Hz}$ during $5 \mathrm{~s}$ emitted at the ablation fluence fulfilled the elimination of the cells target.

The rotation of the polarization of the beam in the interaction did not originate significant changes in the ablation threshold within our error bar. However, it is worth noting that the polarization can represent an important influence in photodamage when the ablation is performed by superposition of multipulses that generate interference. Time-resolved, multiwave mixing experiments could be also considered for controlling photothermal effects [43]. Photoinduced nonlinearities can play a key role for cell transport in biological systems, biosensing, and nanophotonic devices [48]. It has been previously reported that extraction of particular electromagnetic conditions governed by ultrafast functions is mandatory for designing real-time applications [49]. Regulation of nonlinear optical effects is fundamental in quantum experiments [50], and chaotic attractor signals could be also considered for developing multiphotonic devices. The challenge of optical damage by non-invasive techniques is still in progress and it can be considered the monitoring by chaos algorithms in sensors. Chaotic synchronization of Rössler circuits for sensing has major advantages in analysis of multidirectional energy transfer [51]. Immediate applications of chaos theory in the development of sensors for photothermal therapy and laser treatments can be considered. Herein, we reported that photoinduced processes monitored by chaotic attractors should be highlighted as a solid base for developing highly sensitive sensors.

\section{Conclusions}

Chaotic Rössler attractors employed in laser ablation processes assisted by sensors are presented. Controlled activation of laser ablation effects induced by photothermal and sequential logic functions were analyzed. Electrical, thermal, and the optical Kerr effects at $532 \mathrm{~nm}$ with nanosecond pulses in the $\mathrm{NiO}$ films were evaluated. Significant changes in the irradiation dynamics contemplated for thermal studies in the $\mathrm{NiO}$ samples were promoted by a self-defocusing effect identified by a polarization-resolved, two-wave mixing. Within this work it was demonstrated that chaotically modulated optoelectronic signals sensitive to irradiation-, polarization-, or wavelength-varying effects in biomarked cells can be a base for designing photothermal actions. 
Author Contributions: H.M.-A. carried out chaotic evaluations and nonlinear optical experiments; M.A.V.-H. prepared and designed the $\mathrm{NiO}$ films; S.P.-B. participated in the preparation of the conditions for measuring the biological samples; M.T.-V. contributed in the electrochemical impedance measurements; B.E.G.-P. was responsible for the biological samples and confocal microscopy analysis; and C.T.-T. elucidated and analyzed the paper from nonlinear experiments involving photodamage and ablation in $\mathrm{NiO}$ thin films and biological cells. The manuscript was written through the contribution of all authors. All authors have read and agreed to the published version of the manuscript.

Funding: The authors kindly acknowledge the financial support from the Instituto Politécnico Nacional, Comisión de Operación y Fomento de Actividades Académicas del Instituto Politécnico Nacional (COFAA-IPN), and Consejo Nacional de Ciencia y Tecnología (grant CB-2015-251201). The authors are also thankful to the Central Microscopy facilities of the Centro de Nanociencias y Nano y Micro Nanotecnologías del Instituto Politécnico Nacional (CNMN-IPN).

Acknowledgments: The authors kindly acknowledge the financial support from the Instituto Politécnico Nacional, COFAA-IPN, and Consejo Nacional de Ciencia y Tecnología. The authors are also thankful to the Central Microscopy facilities of the Centro de Nanociencias y Micro y Nanotecnologías del Instituto Politécnico Nacional.

Conflicts of Interest: The authors declare no conflict of interest.

\section{References}

1. He, Y.; Zhang, J.; Singh, S.; Garcell, E.; Vorobyev, A.Y.; Lam, B.; Zhan, Z.; Yang, J.; Guo, C. Maskless laser nano-lithography of glass through sequential activation of multi-threshold ablation. Appl. Phys. Lett. 2019, 114, 133107. [CrossRef]

2. Hua, J.G.; Ren, H.; Jia, A.; Tian, Z.N.; Wang, L.; Juodkazis, S.; Chen, Q.D.; Sun, H.B. Convex silica microlens arrays via femtosecond laser writing. Opt. Lett. 2020, 45, 636-639. [CrossRef] [PubMed]

3. Jalil, S.A.; Lai, B.; ElKabbash, M.; Zhang, J.; Garcell, E.M.; Singh, S.; Guo, C. Spectral absorption control of femtosecond laser-treated metals and application in solar-thermal devices. Light Sci. Appl. 2020, 9, 14. [CrossRef] [PubMed]

4. Zhou, L.; Jiang, Y.; Zhang, P.; Wei, H.; Fan, W.; Li, X.; Zhu, J. Numerical and Experimental Investigation of Morphological Modification on Fused Silica Using CO2 Laser Ablation. Materials 2019, 12, 4109. [CrossRef] [PubMed]

5. Müller, D.W.; Fox, T.; Grützmacher, P.G.; Suarez, S.; Mücklich, F. Applying Ultrashort Pulsed Direct Laser Interference Patterning for Functional Surfaces. Sci. Rep. 2020, 10, 3647. [CrossRef] [PubMed]

6. Garcia-Lechuga, M.; Utéza, O.; Sanner, N.; Grojo, D. Evidencing the nonlinearity independence of resolution in femtosecond laser ablation. Opt. Lett. 2020, 45, 952-955. [CrossRef]

7. Huang, F.; Lei, M.; Wang, J.; Chen, D.; Gao, T.; Wang, X. Sound waves generated by nanosecond and femtosecond laser ablation on different metals. Optik 2019, 178, 1131-1136. [CrossRef]

8. Zhang, D.; Wu, J.; Chen, Z.; Lu, Y.; Shi, H.; Wang, G.; Xiao, D.; Ding, N.; Li, X.; Jia, S.; et al. Plasma formation and ablation dynamics of stainless steel cylindrical liner. Phys. Plasmas 2020, 27, 62709. [CrossRef]

9. Zhao, J.; Zhu, Z.; Xu, Y.; Song, X.; Wang, Y.; Peng, H.; Wang, Y.; Zuo, J.; Shu, X.; Yin, A. Nanosecond Laser Ablation of Ti-6Al-4V under Different Temperature. Appl. Sci. 2020, 10, 4657. [CrossRef]

10. Takahashi, T.; Tani, S.; Kuroda, R.; Kobayashi, Y. Precision measurement of ablation thresholds with variable pulse duration laser. Appl. Phys. A 2020, 126, 582. [CrossRef]

11. Parimon, N.; Mamat, M.H.; Shameem Banu, I.B.; Vasimalai, N.; Ahmad, M.K.; Suriani, A.B.; Mohamed, A.; Rusop, M. Fabrication, structural, optical, electrical, and humidity sensing characteristics of hierarchical $\mathrm{NiO}$ nanosheet/nanoball-flower-like structure films. J. Mater. Sci. Mater. Electron. 2020, 31, 11673-11687. [CrossRef]

12. Wu, W.; Wang, M.; Ma, J.; Cao, Y.; Deng, Y. Electrochromic Metal Oxides: Recent Progress and Prospect. Adv. Electron. Mater. 2018, 4, 1800185. [CrossRef]

13. Banerjee, W. Challenges and Applications of Emerging Nonvolatile Memory Devices. Electronics 2020, 9, 1029. [CrossRef]

14. Diao, C.C.; Huang, C.Y.; Yang, C.F.; Wu, C.C. Morphological, Optical, and Electrical Properties of p-Type Nickel Oxide Thin Films by Nonvacuum Deposition. Nanomaterials 2020, 10, 636. [CrossRef] [PubMed]

15. Al-Ghamdi, A.A.; Abdel-wahab, M.S.; Farghali, A.A.; Hasan, P.M.Z. Structural, optical and photo-catalytic activity of nanocrystalline $\mathrm{NiO}$ thin films. Mater. Res. Bull. 2016, 75, 71-77. [CrossRef] 
16. Amin, R.S.; Hameed, R.M.A.; El-Khatib, K.M.; Youssef, M.E.; Elzatahry, A.A. Pt-NiO/C anode electrocatalysts for direct methanol fuel cells. Electrochim. Acta 2012, 59, 499-508. [CrossRef]

17. Varghese, B.; Reddy, M.V.; Yanwu, Z.; Lit, C.S.; Hoong, T.C.; Subba Rao, G.V.; Chowdari, B.V.R.; Wee, A.T.S.; Lim, C.T.; Sow, C.H. Fabrication of $\mathrm{NiO}$ nanowallelectrodes for high performance lithium ion battery. Chem. Mater. 2008, 20, 3360-3367. [CrossRef]

18. Ren, Y.; Chim, W.K.; Guo, L.; Tanoto, H.; Pan, J.; Chiam, S.Y. The coloration anddegradation mechanisms of electrochromic nickel oxide. Sol. Energy Mater. Sol. Cells 2013, 116, 83-88. [CrossRef]

19. Zhang, X.; Shi, W.; Zhu, J.; Zhao, W.; Ma, J.; Mhaisalkar, S.; Maria, T.L.; Yang, Y.; Zhang, H.; Hng, H.H.; et al. Synthesis of porous $\mathrm{NiO}$ nanocrystals with controllable surface area and their application as supercapacitor electrodes. Nano Res. 2010, 3, 643-652. [CrossRef]

20. Irwin, M.D.; Buchholz, D.B.; Hains, A.W.; Chang, R.P.H.; Marks, T.J. P-Type semiconducting nickel oxide as an efficiency-enhancing anode interfaciallayer in polymer bulk-heterojunction solar cells. Proc. Natl. Acad. Sci. USA 2008, 105, 2783-2787. [CrossRef]

21. Liu, B.; Yang, H.; Zhao, H.; An, L.; Zhang, L.; Shi, R.; Wang, L.; Bao, L.; Chen, Y. Synthesis and enhanced gas-sensing properties of ultralong $\mathrm{NiO}$ nanowires assembled with $\mathrm{NiO}$ nanocrystals. Sens. Actuators B 2011, 156, 251-262. [CrossRef]

22. Ying, K.; Liang, H.; Chen, D.; Sun, Y.; Pi, H.; Wei, F.; Yang, F.; Cai, H. Ultralow noise DFB fiber laser with self-feedback mechanics utilizing the inherent photothermal effect. Opt. Express 2020, 28, 23717-23727. [CrossRef] [PubMed]

23. Zangeneh-Nejad, F.; Fleury, R. Topological analog signal processing. Nat. Commun. 2019, 10, 2058. [CrossRef]

24. Martines-Arano, H.; García-Pérez, B.E.; Vidales-Hurtado, M.A.; Trejo-Valdez, M.; Hernández-Gómez, L.H.; Torres-Torres, C. Chaotic Signatures Exhibited by Plasmonic Effects in Au Nanoparticles with Cells. Sensors 2019, 19, 4728. [CrossRef]

25. Rosalie, M. Templates and subtemplates of Rössler attractors from a bifurcation diagram. J. Phys. A Math. Theor. 2016, 49, 315101. [CrossRef]

26. Wang, B.; Zou, F.C.; Cheng, J. A memristor-based chaotic system and its application in image encryption. Optik 2018, 154, 538-544. [CrossRef]

27. Lorenz, E.N. Deterministic Nonperiodic Flow. J. Atmos. Sci. 1963, 20, 130. [CrossRef]

28. Sprott, J.C. Some simple chaotic flows. Phys. Rev. 1994, 50, 647. [CrossRef] [PubMed]

29. Chen, G.; Ueda, T. Yet Another Chaotic Attractor. Int. J. Bifurcat. Chaos 1963, 9, 1465. [CrossRef]

30. Rössler, O.E. An equation for continuous chaos. Phys. Lett. A 1976, 57, 397. [CrossRef]

31. Shekhar, S.C.; Gary, R.; Jin, J.; Mingyan, L.; Andrew, M.K.; Imants, D.S.; Stuart, C. Chaotic Sensing. IEEE Trans. Image Process. 2018, 27, 12.

32. Naruse, M.; Terashima, Y.; Uchida, A.; Kim, S.J. Ultrafast photonic reinforcement learning based on laser chaos. Sci. Rep. 2017, 7, 8772. [CrossRef] [PubMed]

33. Ye, G.; Huang, X. A novel block chaotic encryption scheme for remote sensing image. Multimed. Tools Appl. 2016, 75, 11433. [CrossRef]

34. Huang, X.; Ye, G. An image encryption algorithm based on hyper-chaos and DNA sequence. Multimed. Tools Appl. 2014, 72, 57-70. [CrossRef]

35. Chang, C.Y.; Choi, D.; Locquet, A.; Wishon, M.J.; Merghem, K.; Ramdane, A.; Lelarge, F.; Martinez, A.; Citrin, D.S. A multi-GHz chaotic optoelectronic oscillator based on laser terminal voltage. Appl. Phys. Lett. 2016, 108, 191109. [CrossRef]

36. Liu, Y.; Tang, J.; Xie, T. Cryptanalyzing a RGB image encryption algorithm based on DNA encoding and chaos map. Opt. Laser Technol. 2014, 60, 111-115. [CrossRef]

37. González-Salas, J.S.; Shbat, M.S.; Ordaz-Salazar, F.C.; Simón, J. Analyzing Chaos Systems and Fine Spectrum Sensing Using Detrended Fluctuation Analysis Algorithm. Math. Probl. Eng. 2016, 18, 2865195. [CrossRef]

38. Xi, T.; Zheng-Mao, W.; Jia-Gui, W.; Tao, D.; Jian-Jun, C.; Li, F.; Zhu-Qiang, Z.; Guang-Qiong, X. Tbits/s physical random bit generation based on mutually coupled semiconductor laser chaotic entropy source. Opt. Express 2015, 23, 33130-33141.

39. Bueno, J.; Maktoobi, S.; Froehly, L.; Fischer, I.; Jacquot, M.; Larger, L.; Brunner, D. Reinforcement learning in a large-scale photonic recurrent neural network. Optica 2018, 5, 756-760. [CrossRef]

40. Bentley, C.L.; Perry, D.; Unwin, P.R. Stability and Placement of Ag/AgCl Quasi-Reference Counter Electrodes in Confined Electrochemical Cells. Anal. Chem. 2018, 90, 7700-7707. [CrossRef] 
41. Bell, J.G. Nonlinear Instabilities in Chemical and Electrochemical Systems. Ph.D. Thesis, University of Windsor, Windsor, ON, Canada, 2017.

42. Ibrahim, K.M.; Jamal, R.K.; Ali, F.H. Chaotic behaviour of the Rossler model and its analysis by using bifurcations of limit cycles and chaotic attractors. J. Phys. Conf. Ser. 2018, 1003, 12099. [CrossRef]

43. Hernández-Acosta, M.A.; Martines-Arano, H.; Soto-Ruvalcaba, L.; Martínez-González, C.L.; Martínez-Gutiérrez, H.; Torres-Torres, C. Fractional thermal transport and twisted light induced by an optical two-wave mixing in single-wall carbon nanotubes. Int. J. Therm. Sci. 2020, 147, 106136. [CrossRef]

44. Boyd, R.W. Nonlinear Optics; Academic Press: Cambridge, MA, USA, 1992.

45. Sheik-Bahae, M.; Said, A.A.; Wei, T.; Hagan, D.J.; Stryland, E.W.V. Sensitive measurement of optical nonlinearities using a single beam. IEEE J. Quantum Electron. 1990, 26, 760. [CrossRef]

46. Lee, H.E.; Kim, S.; Ko, J.; Yeom, H.I.; Byun, C.W.; Lee, S.H.; Joe, D.J.; Im, T.H.; Park, S.H.K.; Lee, K.J. Skin-Like Oxide Thin-Film Transistors for Transparent Displays. Adv. Funct. Mater. 2016, 26, 6170-6178. [CrossRef]

47. De Melo, R.P., Jr.; da Silva, B.J.P.; dos Santos, F.E.P.; Azevedo, A.; de Araújo, C.B. Nonlinear refraction properties of nickel oxide thin films at $800 \mathrm{~nm}$. J. Appl. Phys. 2009, 106, 93517. [CrossRef]

48. Cesca, T.; Michieli, N.; Kalinic, B.; Balasa, I.G.; Rangel-Rojo, R.; Reyes-Esqueda, J.A.; Mattei, G. Bidimensional ordered plasmonic nanoarrays for nonlinear optics, nanophotonics and biosensing applications. Mat. Sci. Semicond. Proc. 2019, 92, 2-9. [CrossRef]

49. Torres-Torres, R. Extracting characteristic impedance in low-loss substrates. Electron. Lett. 2011, 47, $191-193$. [CrossRef]

50. Hernández-Acosta, M.A.; Trejo-Valdez, M.; Castro-Chacón, J.H.; Torres-SanMiguel, C.R.; Martínez-Gutiérrez, H.; Torres-Torres, C. Chaotic signatures of photoconductive Cu2ZnSnS4 nanostructures explored by Lorenz attractors. N. J. Phys. 2018, 20, 23048. [CrossRef]

51. Sambas, A.; Sanjaya, M.; Mamat, M.; Halimatussaiyah, W.S. Design and Analysis Bidirectional Chaotic Synchronization of Rossler Circuit and Its Application for Secure Communication. App. Math. Sci. 2013, 1, 11-21. [CrossRef]

Publisher's Note: MDPI stays neutral with regard to jurisdictional claims in published maps and institutional affiliations.

(C) 2020 by the authors. Licensee MDPI, Basel, Switzerland. This article is an open access article distributed under the terms and conditions of the Creative Commons Attribution (CC BY) license (http://creativecommons.org/licenses/by/4.0/). 